\title{
Modelling rail corrugation with specific track parameters focusing on ballasted track and slab track
}

\author{
O. OYARZABAL*, N. CORREA, E. G. VADILLO, J. SANTAMARIA, J. GÓMEZ
}

Department of Mechanical Engineering. University of the Basque Country

UPV/EHU. Alameda Urquijo s.n., 48013 Bilbao, Spain

NOTICE: This is an Author's Accepted Manuscript of an article published in VEHICLE SYSTEM DYNAMICS, Vol. 49, № 11, pp. 1733-1748 on November 2011 [copyright Taylor \& Francis], available online at:

http://www.tandfonline.com/10.1080/00423114.2010.536557

DOI: $10.1080 / 00423114.2010 .536557$

\begin{abstract}
Please cite this paper as: Oyarzabal, O., J., Correa, N., Vadillo, E.G., Santamaria, J., Gomez, J. Modelling rail corrugation with specific track parameters focusing on ballasted track and slab track. Vehicle System Dynamics, Vol. 49, pp. 1733-1748. 2011
\end{abstract}

\footnotetext{
* Corresponding autor. Email: olatz.oyarzabal@ehu.es
} 


\title{
Modelling rail corrugation with specific track parameters focusing on ballasted track and slab track
}

\author{
O. Oyarzabal*, N. Correa, E. G. Vadillo, J. Santamaria, J. Gómez \\ Mechanical Engineering Department, University of the Basque Country UPV/EHU, \\ Escuela Superior de Ingeniería, Alda. Urquijo s/n, 48013 Bilbao, Spain
}

\begin{abstract}
The objective of this paper is to compare 3 types of track (high performance ballasted track, STEDEF and AFTRAV) from the corrugation growth point of view. This work has considered different vehicle speeds and track radii, and the results have taken into account the four wheels of a bogie.

These tracks have been studied using Finite Elements with Nastran-Patran and RACING, a tool developed in Matlab by the authors which estimates the corrugation growth tendency. The tracks are studied using the Finite Strip Method and the Periodic Structure Theory. Lateral and vertical receptances for track and vehicle have been obtained, as well as the corrugation growth functions. In the paper the tracks are ranked according to corrugation development.
\end{abstract}

Keywords: rail corrugation; slab track; ballasted track.

\section{Introduction}

The use of slab track has been greatly extended in the last decades. One example of this can be found in Japan, which has used this type of track for more than 25 years. Constructing a slab track is, in general, more expensive than building a ballasted track. However, its high geometric stability allows a significant reduction of track maintenance and conservation operations.

In Spain new lines are being built, using both types of track. In this paper, at the request of CEDEX (Centre for Studies and Experimentation in Public Works), three types of tracks are compared from the corrugation point of view. Two of them are slab tracks (STEDEF and AFTRAV track) and the other is a high performance ballasted track.

Rail corrugation is an important problem that has been examined in numerous studies. It is an undulatory wear that appears in the surface of the rail. Its development causes noise and vibrations, and therefore it must be eliminated, which requires large amounts of track maintenance. A thorough classification of corrugation types was made by Grassie and Kalousek in 1993 [1] including corrugation characteristics, causes and treatments. More recent and extended work by Grassie in this field can be found in $[2,3]$.

Several authors have developed models simulating rail roughness growth considering the interaction of a wheelset with the track. Some of those models include advanced wheel-rail contact approaches [4, 5], and in some cases non-Hertzian models have been considered [6,7]. Moreover, the contact induced wear filtering and its effect on corrugation development has also been considered [8]. 
Torstensson and Nielsen have studied the irregular wear and its monitoring [9]. Apart from this, discrete supports, which have an important influence on rail corrugation, have also been taken into account $[10,11]$. Likewise, there are models in which the multiple wheel-rail interactions have been considered $[12,13]$.

Several solutions to the rail corrugation problem have been proposed, including rail dampers [14] as well as lubrication between wheel tread and the top of low rail in sharp curves [15]. Friction modifiers have an important role in wheel-rail contact [16], and their effect has been included in the rail corrugation modelling in curves [17].

In the present paper two types of slab track are compared to the ballasted track from the corrugation point of view.

The parameters used in this work for each type of track are standard parameters. However, currently many types of ballasted track and slab track are developed so that the range of track parameters, vertical and lateral stiffness and damping, of both ballast and slab track are enlarged as much as possible. It must also be kept in mind that the ballasted tracks as well as the slab tracks have some variations due to the combination of all possible rail fastening systems, and all this could lead to variations in the results shown in this work.

Nevertheless, the three types of track used for this study have structural differences that make difficult that a combination of parameters of one of the tracks could lead to a dynamic response that overlapped with the response of any of the other two: the STEDEF track has bi-block sleepers, while the high performance ballasted track always uses heavy monoblock sleepers, and the AFTRAV track has no sleeper separated from the slab. In the case of the slab tracks considered none of them are floating slab tracks.

\section{Types of track studied}

All the analysed tracks are standard gage $(1435 \mathrm{~mm})$ and use UIC60 rail. They are the following:

\subsection{STEDEF track}

It is a continuous slab track with two elastic levels. The sleepers are constructed with steel reinforced concrete covered with elastic material on their bottom and lateral sides (called boots) and are embedded in the main slab. The distance between sleepers is $0.6 \mathrm{~m}$. (Fig.1.a).

The parameters of this track are as follows: The vertical pad stiffness is 150 $\mathrm{kN} / \mathrm{mm}$, the lateral pad stiffness is $250 \mathrm{kN} / \mathrm{mm}$, the vertical boots stiffness is 25 $\mathrm{kN} / \mathrm{mm}$ and the lateral boots stiffness is $40 \mathrm{kN} / \mathrm{mm}$. The vertical and lateral pad damping, as well as the vertical and lateral boots damping, is 0.2 . The sleeper mass is $221.7 \mathrm{~kg}$.

\subsection{AFTRAV track}

It is constructed from prefabricated slab in a manner that only provides one stage of elasticity. The separation between the elastic supports in this type of track is $0.65 \mathrm{~m}$ (Fig.1.b). The vertical pad stiffness in this track is $40 \mathrm{kN} / \mathrm{mm}$. 
(a)

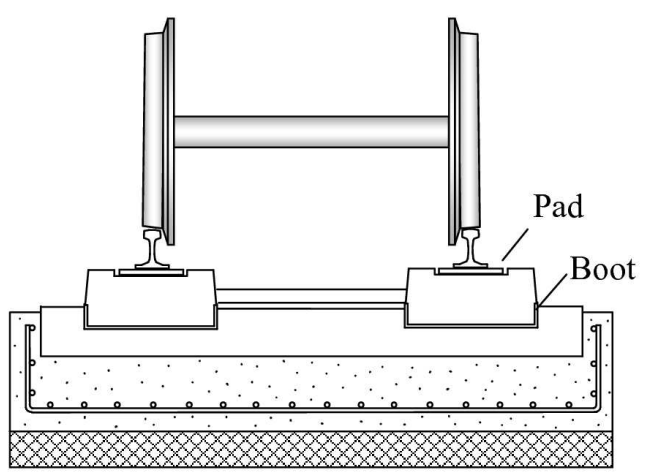

(b)

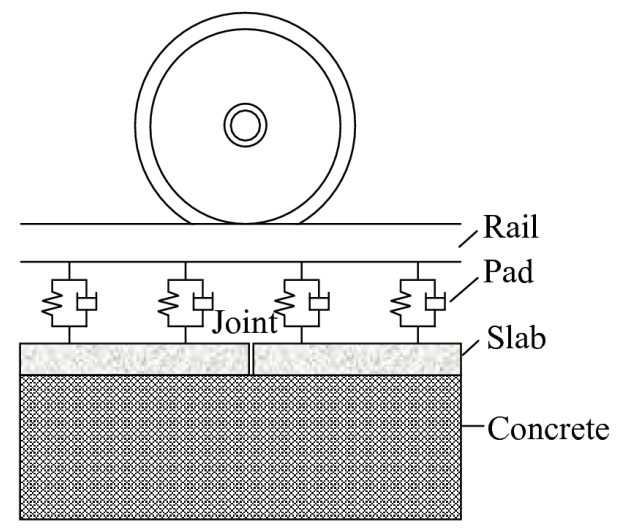

Figure 1. Slab tracks. (a) STEDEF track (b) AFTRAV track.

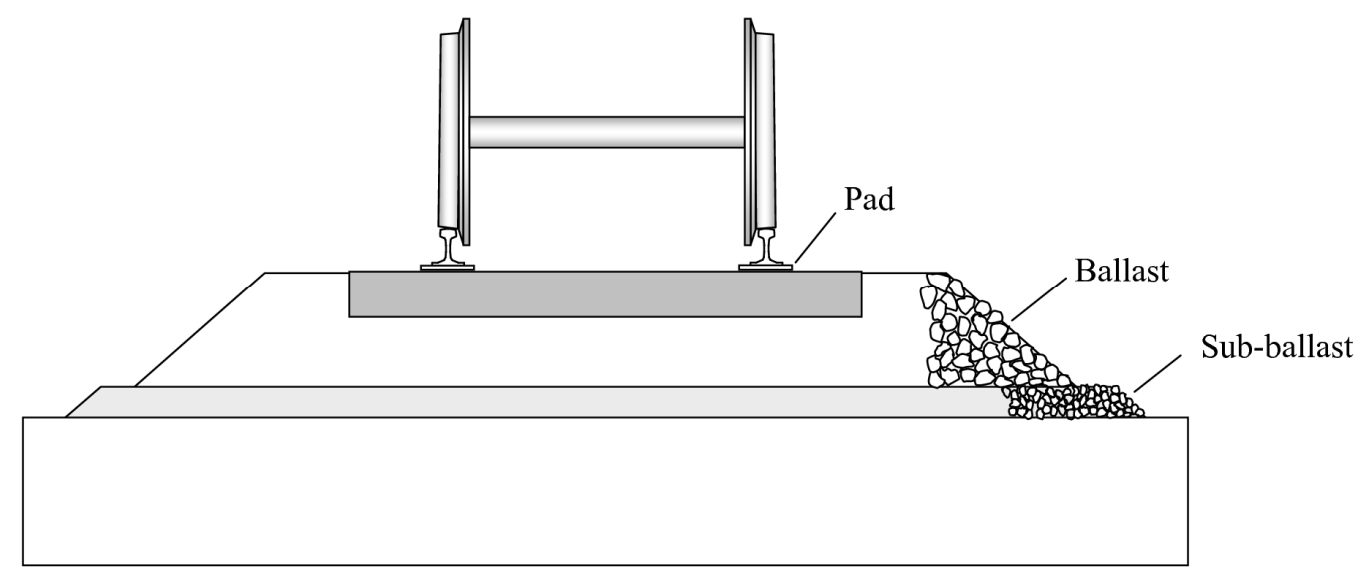

Figure 2. High-performance ballasted track.

\subsection{Ballasted track}

The ballasted track considered in this work is a high performance track in which the sleepers are $0.6 \mathrm{~m}$ apart (Fig.2). The vertical pad stiffness of this track is $100 \mathrm{kN} / \mathrm{mm}$, the lateral pad stiffness is $20 \mathrm{kN} / \mathrm{mm}$, the vertical ballast stiffness is $50 \mathrm{kN} / \mathrm{mm}$ and the lateral ballast stiffness is $13.3 \mathrm{kN} / \mathrm{mm}$. The vertical pad damping is $15000 \mathrm{Ns} / \mathrm{m}$, the lateral pad damping is $5367 \mathrm{Ns} / \mathrm{m}$, the vertical ballast damping is $12300 \mathrm{Ns} / \mathrm{m}$ and the lateral ballast damping is $38750 \mathrm{Ns} / \mathrm{m}$. The sleeper mass is $320 \mathrm{~kg}$. 


\section{Tool utilised: RACING}

In the linear model developed by the authors of this paper [18, 19], which is referred to as RACING, an infinitesimal roughness in the profile of the rail rolling surface generates a feedback process. It is this feedback that produces the undulatory wear on the head of the rail. The initial roughness instigates the infinitesimal variation of the variables that define the contact between wheel and rail. As a result, the variation is transmitted for each excitation frequency to the vehicle and track, having an influence on their dynamic behaviour. The tracks dynamic behaviour is reflected in the track receptances, that have been obtained by RACING which works on the basis of the Finite Strip Method. These receptances have also been validated by the Finite Element program MSC/NASTRAN.

The model requires the quasi-static wheel-rail contact values while negotiating a bend, which are obtained from the DINATREN programme. An explanation of the main features of DINATREN can be found in Ref. [20].

The output of the application is the corrugation growth function, which shows the predisposition to the appearance of corrugation as a function of frequency in $\mathrm{Hz}[21$, 22].

The equation which defines the corrugation process is the following:

$$
\frac{\partial \Delta z}{\partial N}=\lambda \Delta z
$$

The real part of $\lambda$ is denoted as the corrugation growth function, which is adimensional; $N$ denotes axle passes and $\Delta \mathrm{z}$ is the amplitude of the infinitesimal wave.

From equation (1) it is derived that if the growth function is negative over a range of frequency, then, over that range of frequency the corrugation will tend to be erased. Nevertheless, if the growth function is positive, the formation of corrugation will be favoured. Moreover, in this second case, the rougher the initial rail profile, the more rapidly will the corrugation develop.

The concept of growth function has also been employed in [18, 19, 23]. Growth functions are shown along this article in Fig. 4 and figures 12 to 14.

\subsection{Free waves used in RACING}

Point receptances are obtained using the characteristic waves of the rail with support, for excitations applied within the span or over the sleeper.

The calculation time of the free waves has been greatly shortened due to one property of the rail that permits a few free waveshapes at $100 \mathrm{~Hz}$ to be used as section functions for any frequency under study [24].

As an example, the first six free waves of the rail are shown in figure 3 :

(1) Elongation (Fig. 3.a)

(2) Torsion (Fig. 3.b)

(3) Vertical decaying (Fig. 3.c)

(4) Vertical of propagation (Fig. 3.d)

(5) Lateral decaying (Fig.3.e)

(6) Lateral of propagation (Fig. 3.f) 
Different meshes have been utilized and the one illustrated in this paper corresponds to 44 elements and 69 nodes. Taking into account the compromise between precision and numerical problems found when calculating eigenvectors of the coupling transfer matrix (characteristics waves), the 11 least decaying waves are used.

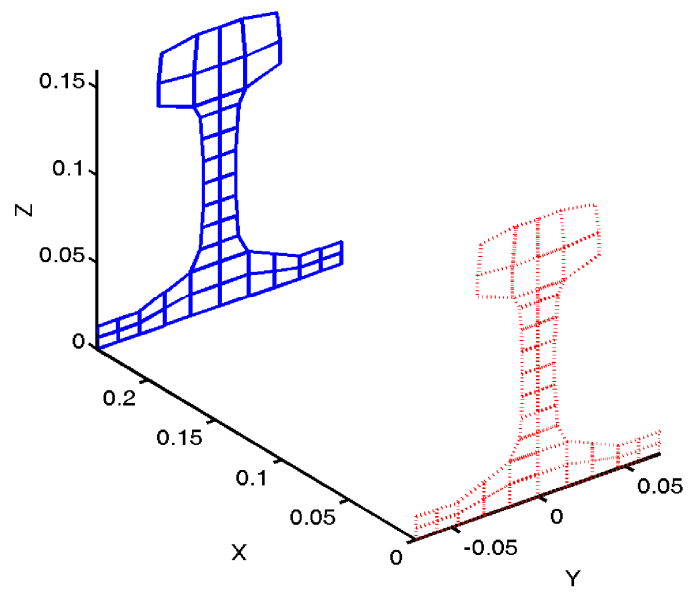

(a)

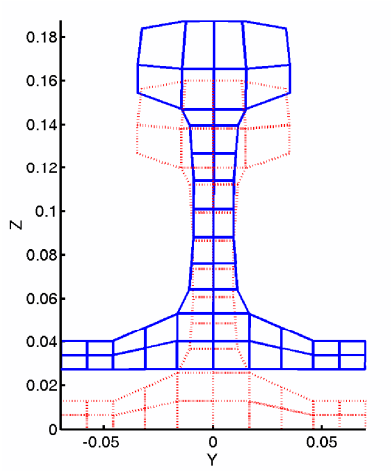

(c)

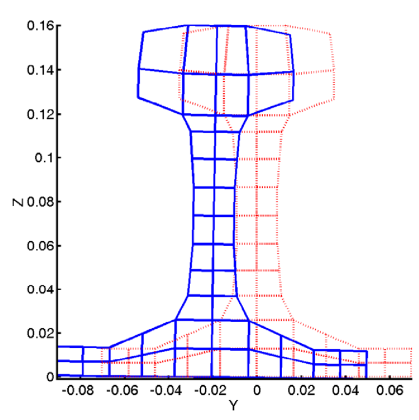

(e)
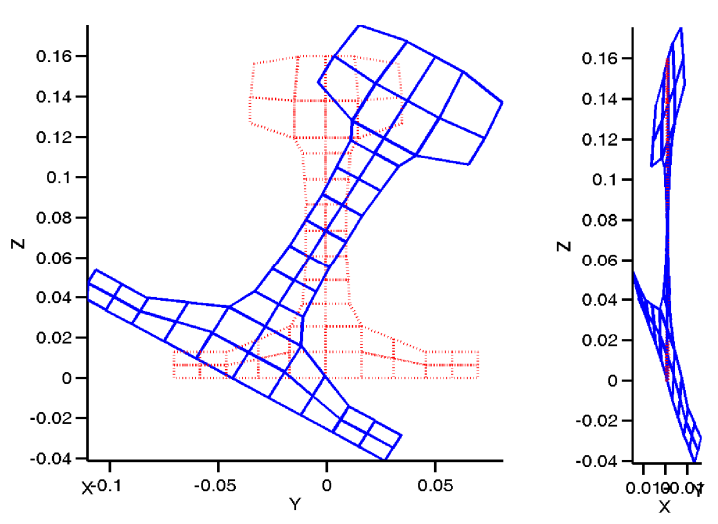

(b)
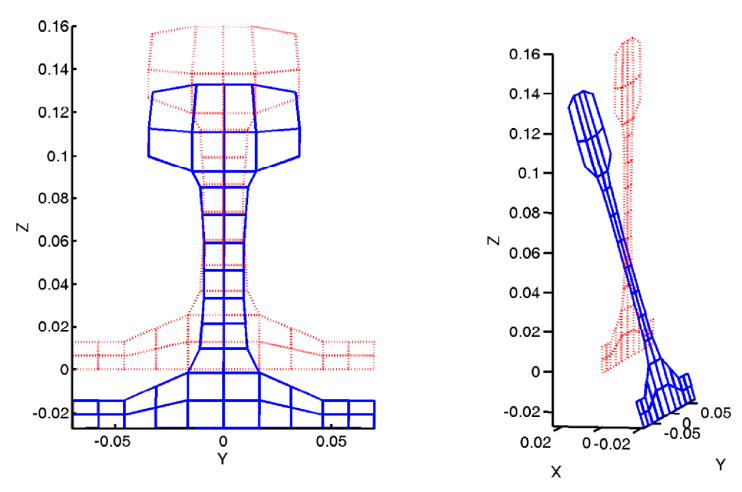

(d)
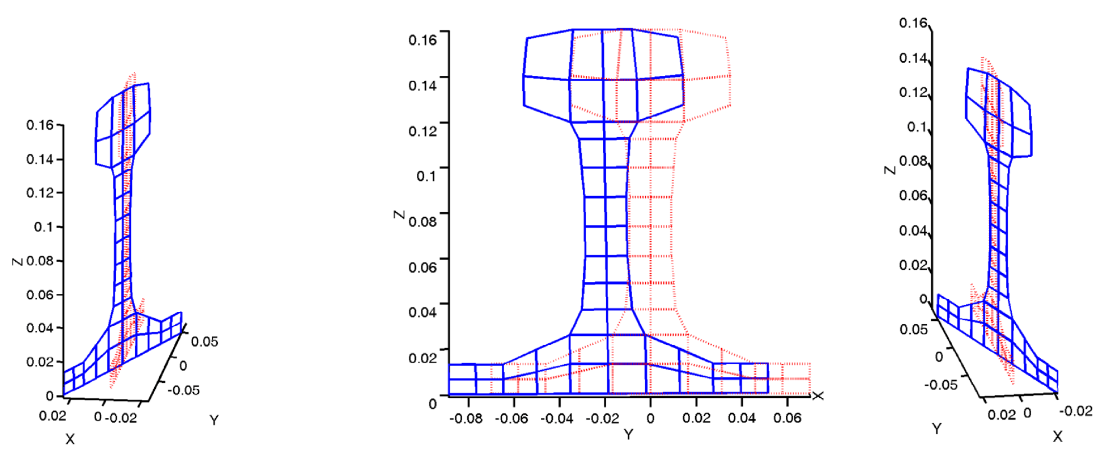

(f)

Figure 3. The first six free waves of the rail. a) Elongation b) Torsion c) Vertical decaying d) Vertical of propagation e) Lateral decaying f) Lateral of propagation 
In order to obtain the characteristic waves it is necessary to include the support in the model. For this purpose, the discontinuous nature of the support along the length of the rail requires the introduction of the basic concepts of Periodic Structure Theory in the calculation.

\subsection{Advantages of RACING for optimization}

It is worth mentioning that the model used by the authors, being in the frequency domain, is very suitable for optimization purposes because the calculation time of the receptance is approximately 100 times faster than with a Finite Element program for an equivalent mesh and rail section. In each optimization process, the calculation of the receptance is completed thousands of times and therefore, if it is done with the FEM it would be much more time consuming.

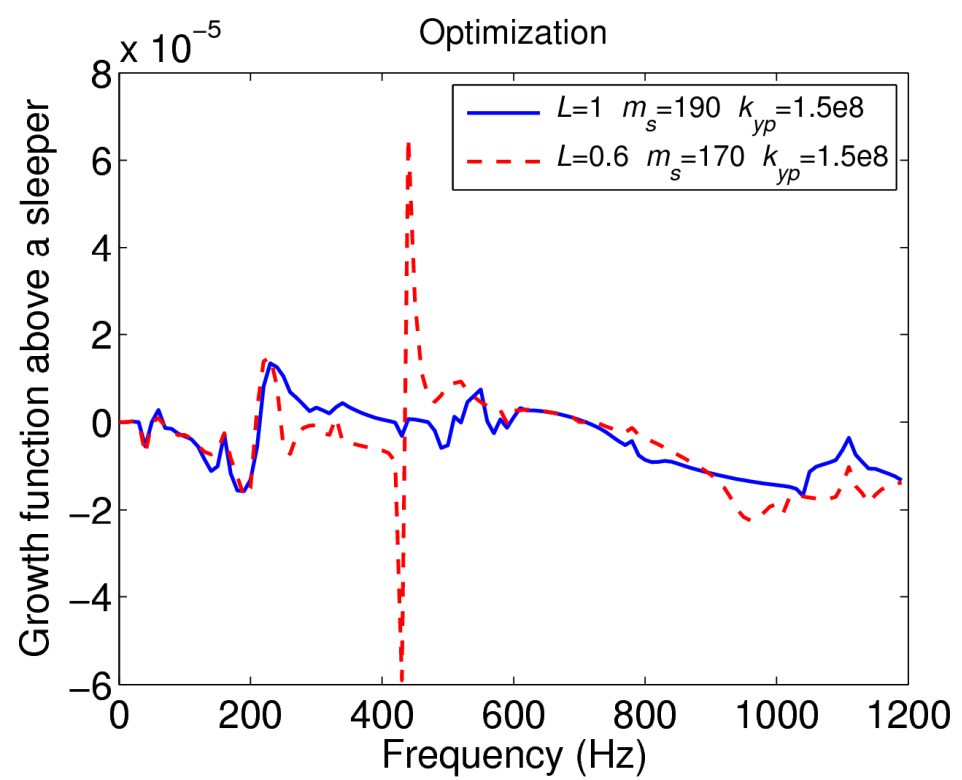

Figure 4. Output obtained from the optimization process for the growth function above a sleeper

Figure 4 shows the improvement reached with the optimization. This improvement has been obtained for the growth function above a sleeper in the STEDEF track using different parameters. The first number of the legend corresponds to $L$, the distance between sleepers; the second number, $m_{s}$, to the sleeper mass; and the last value is $k_{y p}$, the pad vertical stiffness. The improvement obtained with the optimization is very significant. It can be observed how the function is much flatter after the optimization.

\section{Results}

\subsection{Receptances}

The vertical and lateral receptances of the three types of track have been calculated, both at midspan and above a sleeper. These receptances are necessary in order to obtain the corrugation growth function because all the dynamic track behaviour is included in the receptances. 
The receptances of the STEDEF track are shown in figure 5. The lateral $\left(k_{x p}\right)$ and vertical $\left(k_{y p}\right)$ pad stiffnesses are typed at the top of the figures. In the vertical receptance (Fig.5.a) one can observe: the vertical resonance of the sleeper-rail group on the boots of the STEDEF track $(66 \mathrm{~Hz})$; the vertical resonance of the rail on the pad $(350 \mathrm{~Hz})$. The deformation of the rail on the pads generated by MSC/NASTRAN program is shown in figure 6 . The first pinned-pinned vertical mode is at approximately $1076 \mathrm{~Hz}$. The rail deformation for the pinned-pinned frequency can be seen in figure 7.

(a)

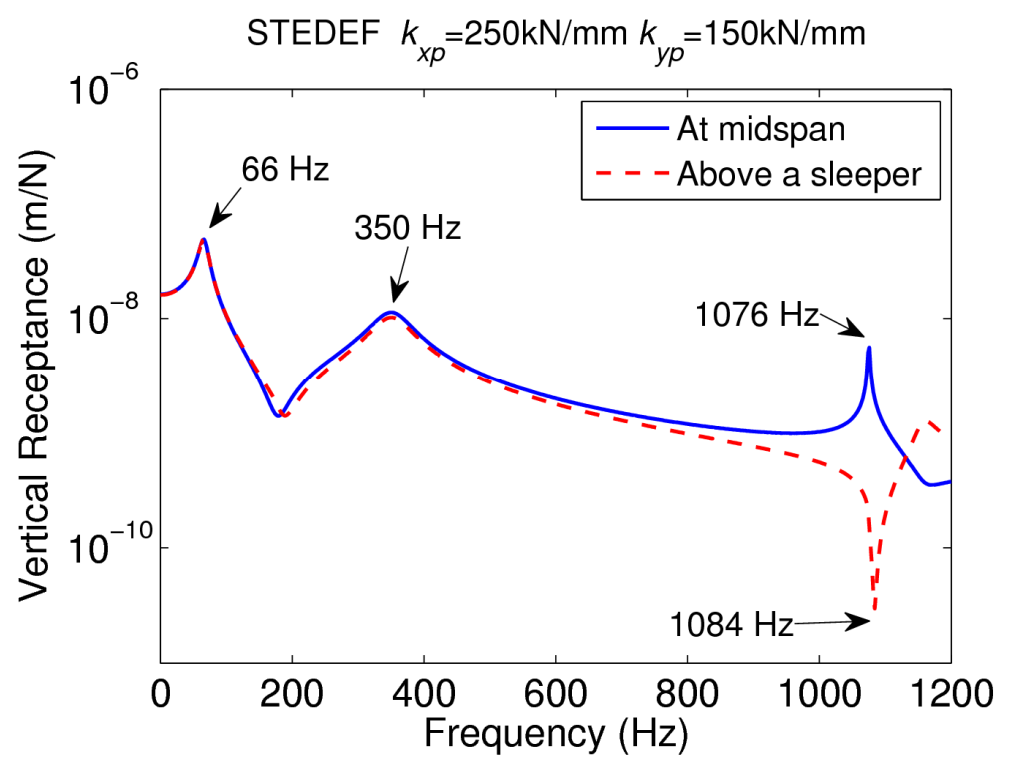

(b)

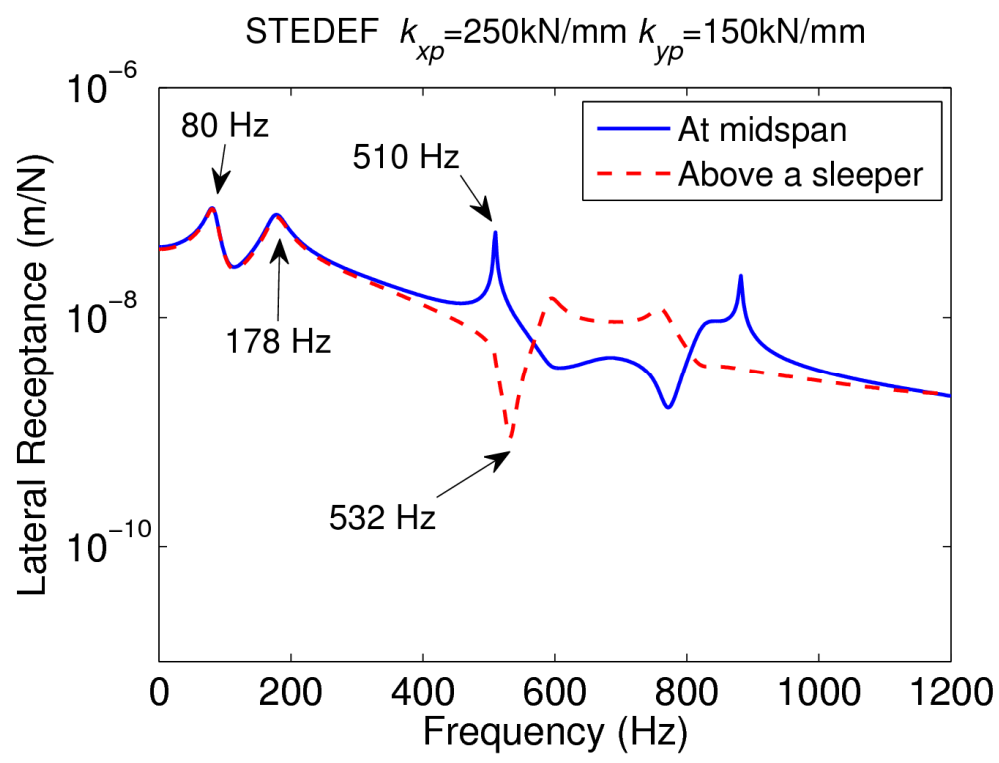

Figure 5. a) Vertical and b) lateral receptance of STEDEF track, at midspan and above sleeper

The lateral receptance of the STEDEF track (Fig.5.b) shows the lateral resonance of the sleeper-rail group on the boots at $80 \mathrm{~Hz}$; the lateral resonance of the rail on the elastic pad at $178 \mathrm{~Hz}$; and the first lateral pinned-pinned mode around $510 \mathrm{~Hz}$. Figure 
8 shows the deformation of the rail corresponding to the lateral pinned-pinned frequency.

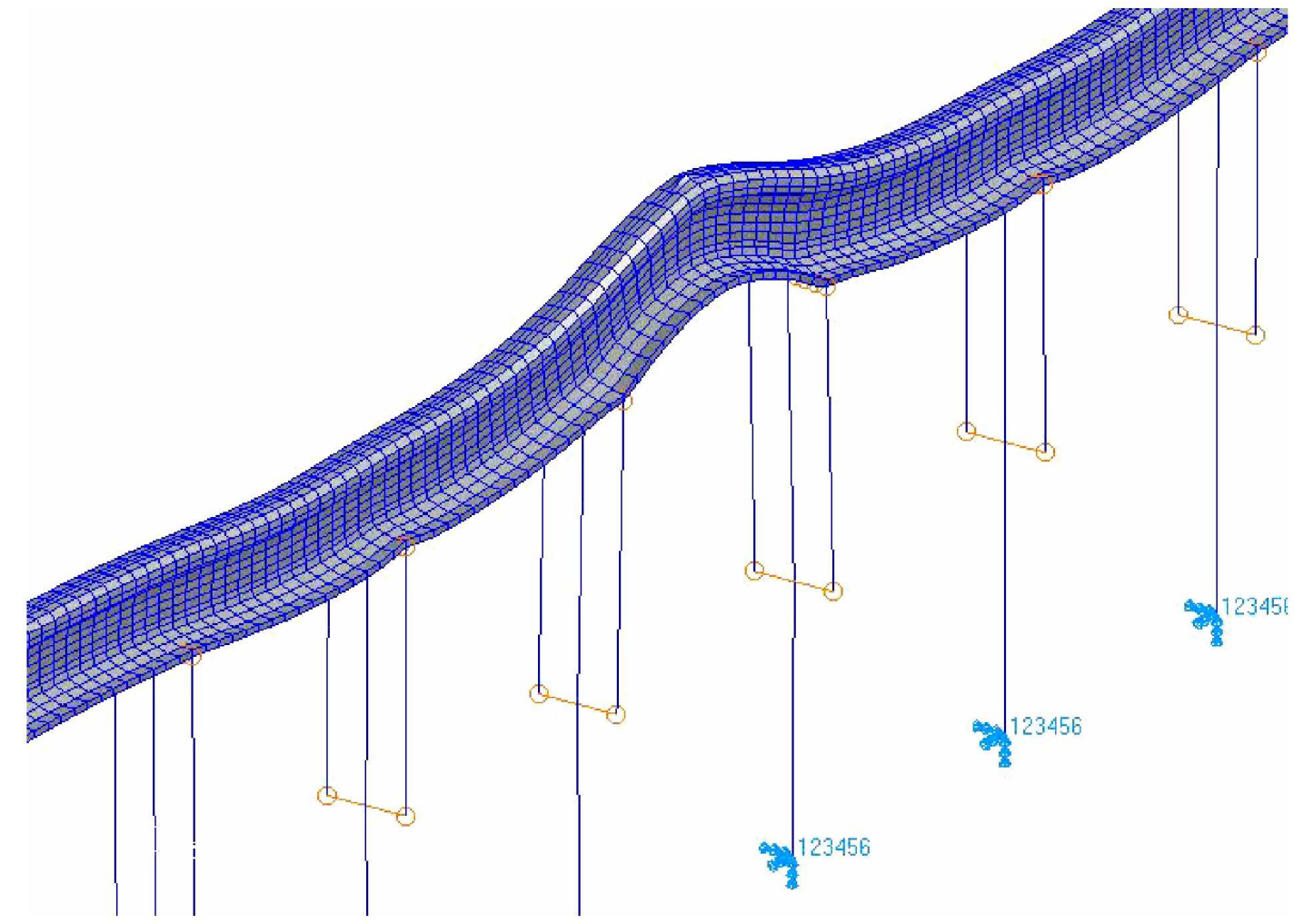

Figure 6. Deformation of the rail on the pads in the STEDEF track

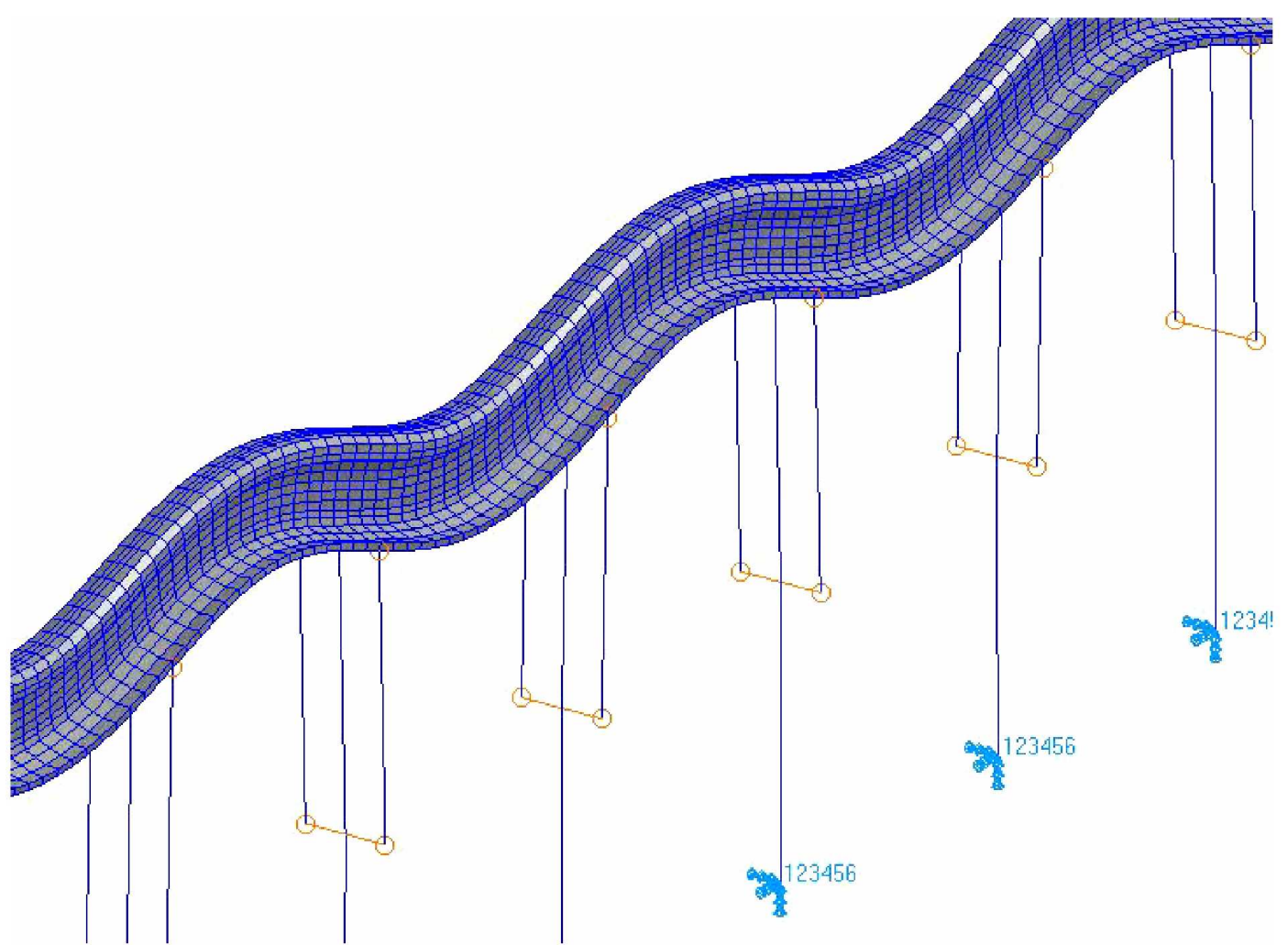

Figure 7. Rail deformation corresponding to the vertical pinned-pinned frequency in the STEDF track 


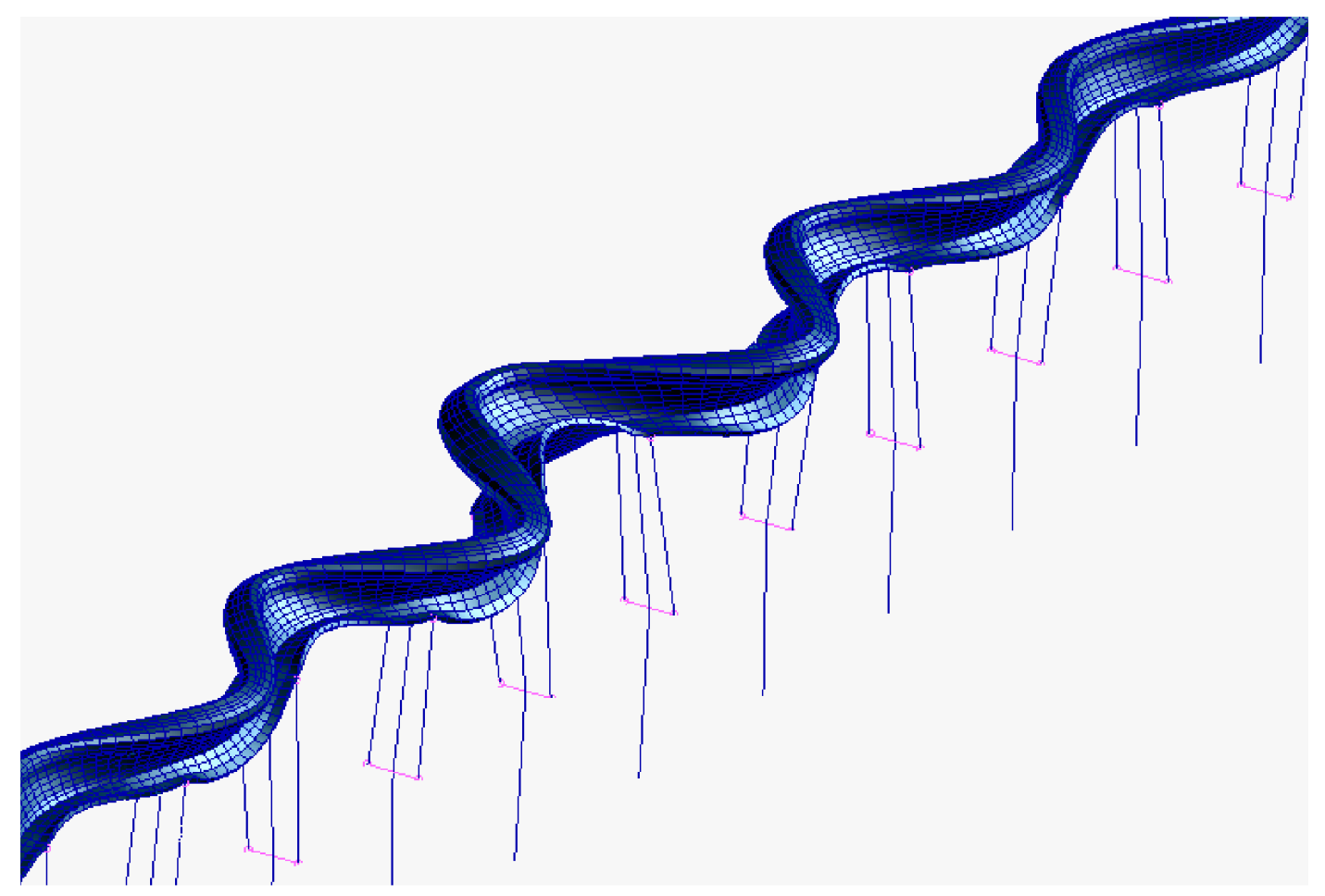

Figure 8. Deformation of the rail at the lateral pinned-pinned frequency in the STEDEF track

Figure 9 reflects the vertical and lateral receptances of the AFTRAV track. The vertical vibration mode of the rail on the elastic pad is at $160 \mathrm{~Hz}$ and the first vertical pinned-pinned at $946 \mathrm{~Hz}$. In the lateral receptance the roll rotation mode of the rail on the pad happens at $90 \mathrm{~Hz}$ and the lateral pinned-pinned frequency is at $442 \mathrm{~Hz}$.

The receptances of the ballasted track are depicted in figure 10. The first resonance that appears is due to the vibration of the rail and sleeper group on the ballast at $80 \mathrm{~Hz}$. The second peak is at $282 \mathrm{~Hz}$ and is due to the vibration of the rail on the pad. The first pinned-pinned mode appears at $1076 \mathrm{~Hz}$. This frequency is the same as in the STEDEF track, because both of them have the same span length of $0.6 \mathrm{~m}$ and the same rail. The peaks in the lateral receptance are at $32 \mathrm{~Hz}$ for the ballast, $106 \mathrm{~Hz}$ for the roll rotation mode of the rail on the pad, and the first lateral pinned-pinned mode occurs at $510 \mathrm{~Hz}$.

The natural frequencies of the wheelset have been obtained, as well as the corresponding modes of vibration. Afterwards the wheelset receptances have been computed because they are necessary for the calculation of the growth functions.

\subsection{Corrugation growth functions}

The growth functions have been calculated for 4 different curve radii and 4 vehicle circulation speeds. They are as follows:

- Radius $3550 \mathrm{~m}$ and speed $250 \mathrm{~km} / \mathrm{h}$ (general track)

- Radius $1000 \mathrm{~m}$ and speed $140 \mathrm{~km} / \mathrm{h}$ (general track)

- Radius $320 \mathrm{~m}$ and speed $45 \mathrm{~km} / \mathrm{h}$ (switches and crossings)

- Radius $150 \mathrm{~m}$ and speed $35 \mathrm{~km} / \mathrm{h}$ (shunting yards) 
(a)

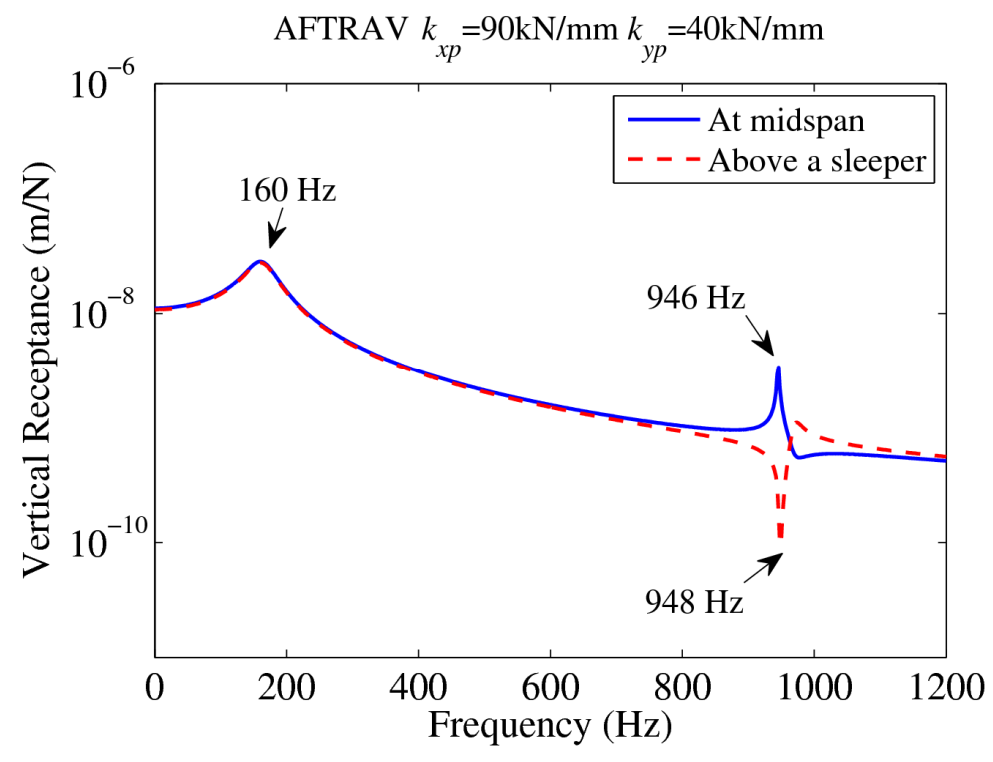

(b)

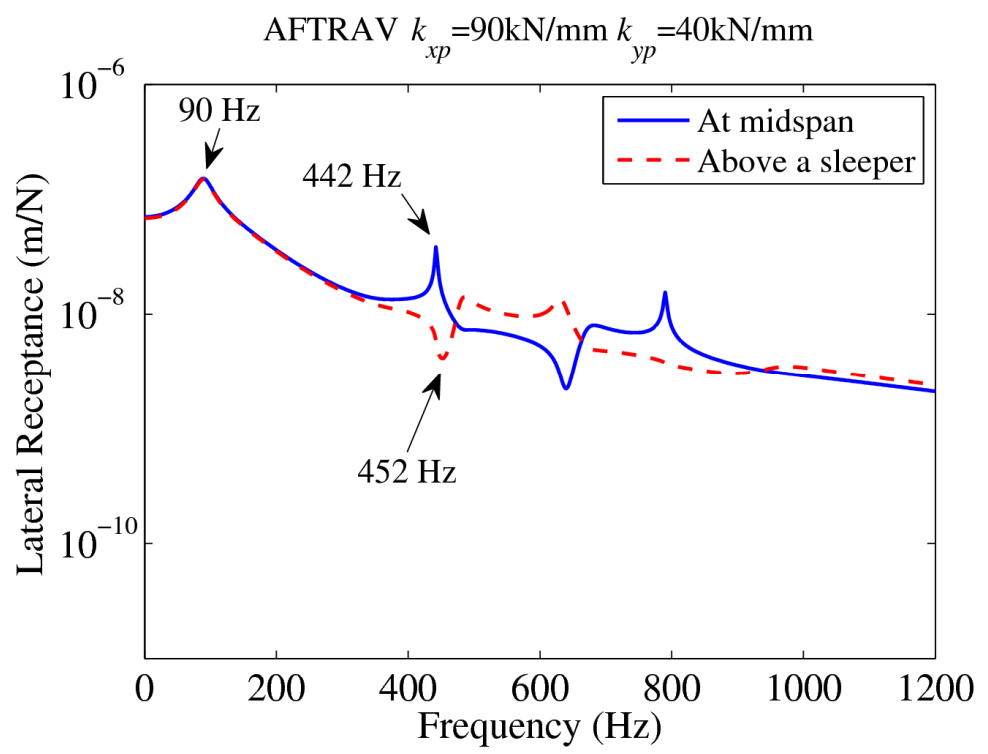

Figure 9. a) Vertical and b) lateral receptance of AFTRAV track, at midspan and above a sleeper

The first two radii are common in main lines on which the vehicle will circulate. The other two occur in very sharp curves, and the vehicle does not pass through them frequently.

The growth functions in longitudinal and lateral directions have been grouped as only one single function, which are shown in the following figures. The corrugation wavelength can easily be obtained from the frequency at which the dominant peak appears in the growth function.

The growth functions of the four wheels of a bogie (as in the diagram of figure 11) have been obtained both for midspan and above a sleeper. The wheels 1 and 2 are the outside and inside wheels of the leading wheelset of the bogie. The wheels 3 and 4 are the outside and inside wheels of the trailing wheelset of the bogie.

In this study 96 growth functions have been analyzed (3 types of track, 4 speeds with each corresponding radius, 4 wheels of a bogie and at midspan and above a sleeper). In order to understand the conclusions reached, the corrugation growth functions of STEDEF track for the 4 wheels of a bogie and the $1000 \mathrm{~m}$ curve radius 
are the first ones to be illustrated (Fig. 12). A radius of $1000 \mathrm{~m}$ is initially selected because it corresponds to an intermediate curvature.

(a)

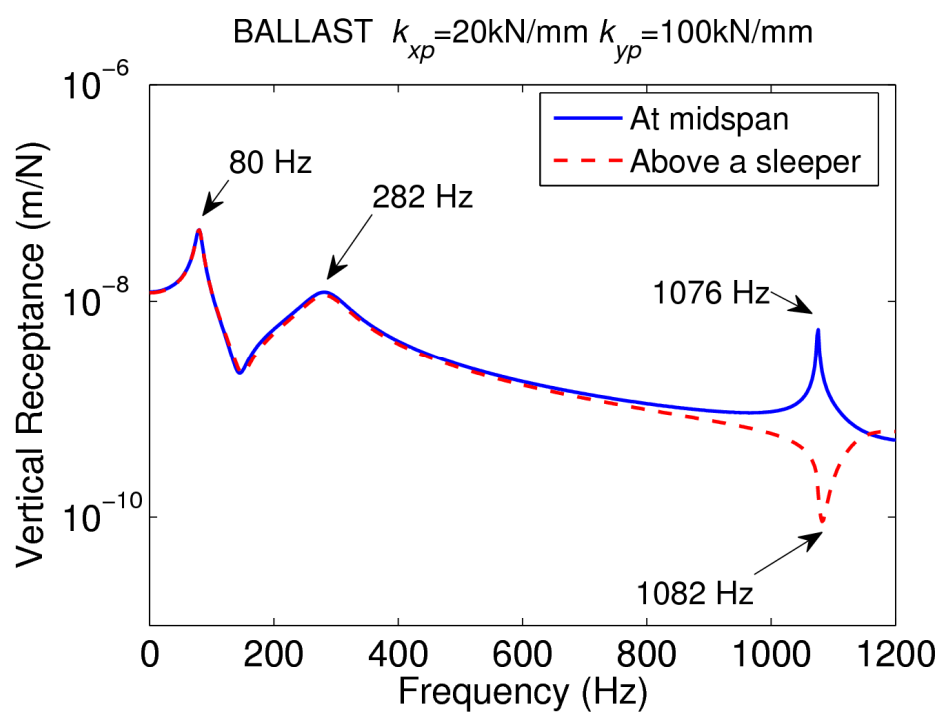

(b)

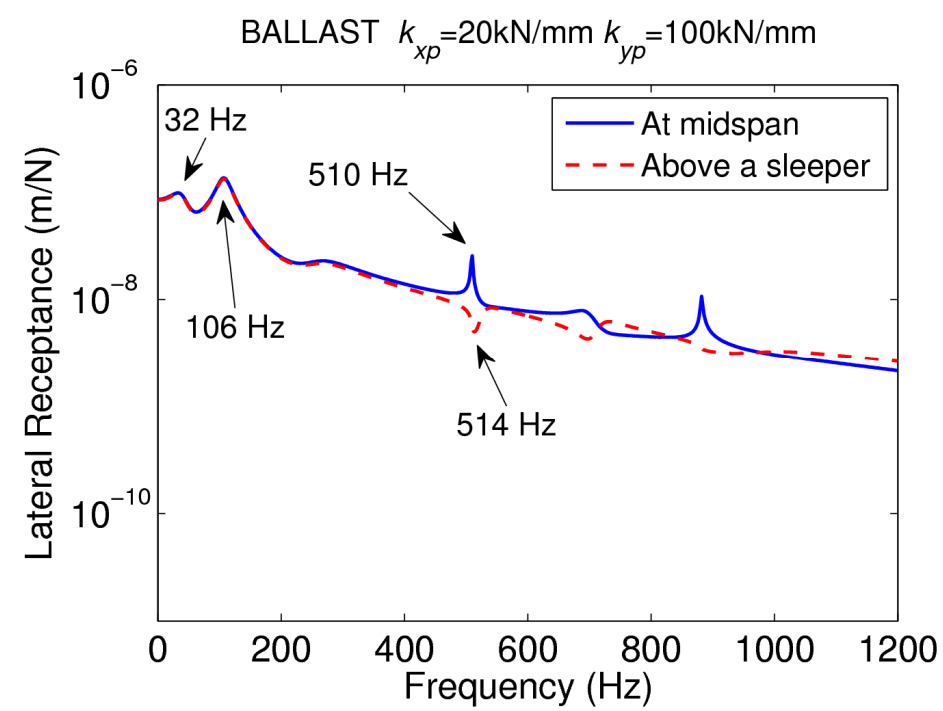

Figure 10. a) Vertical and b) lateral receptance of ballasted track, at midspan and above a sleeper

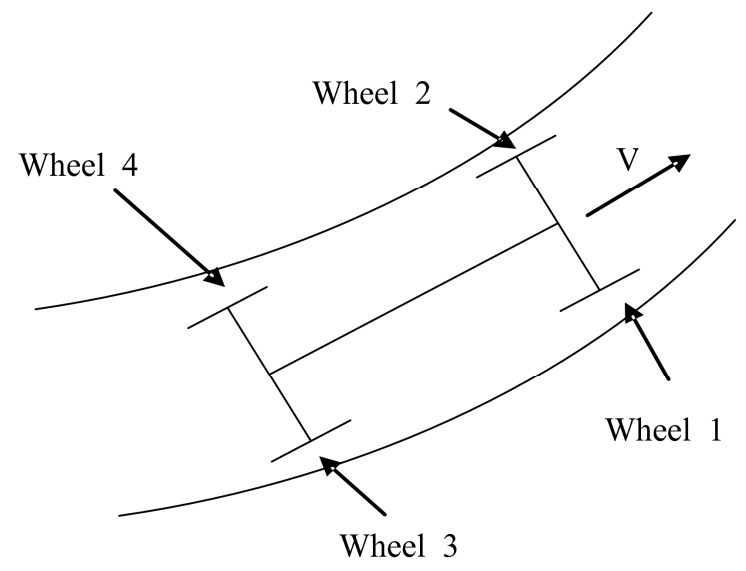

Figure 11. Numbering of the wheels of the bogie 
(a)

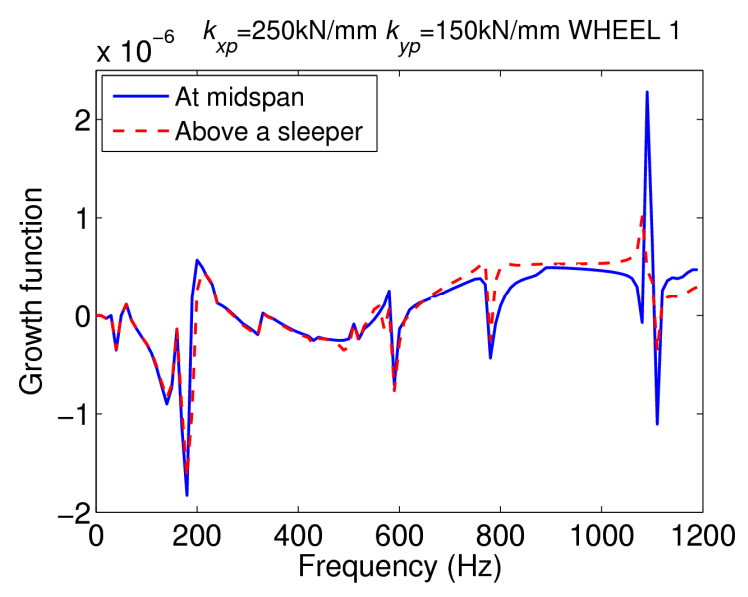

(c)

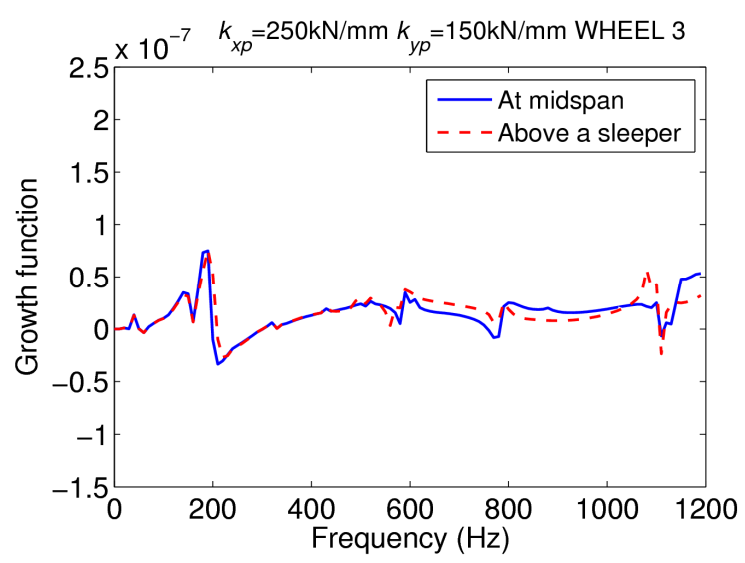

(b)

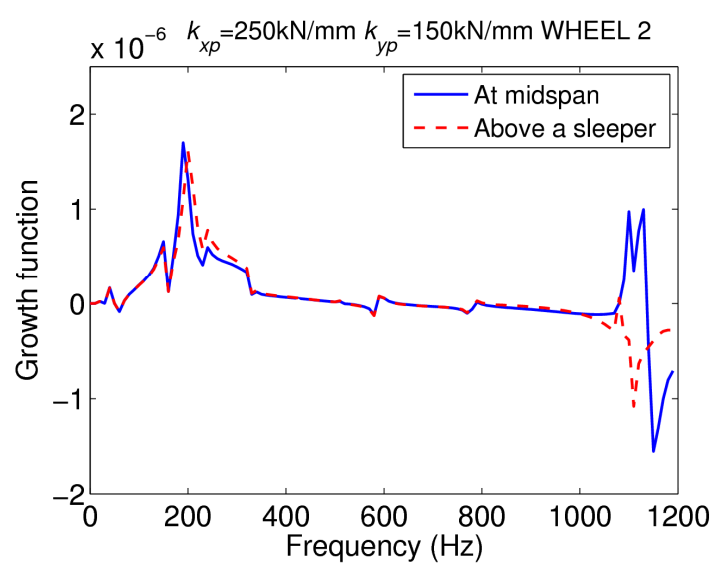

(d)

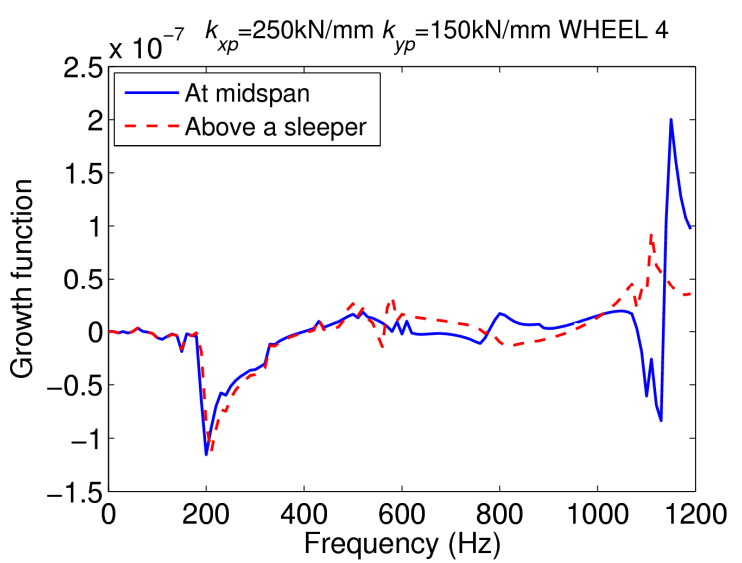

Figure 12. Growth functions at midspan and above a sleeper for the STEDEF track at a speed of $140 \mathrm{~km} / \mathrm{h}$, with a curve radius of $1000 \mathrm{~m}$ for wheels: a) Wheel $1 \mathrm{~b}$ ) Wheel 2 c) Wheel 3 d) Wheel 4

There are two important peaks in these graphs. The maximum value of the growth function, at $1100 \mathrm{~Hz}$, was produced by the passing of Wheel 1 . The next highest value, at $200 \mathrm{~Hz}$, was produced by Wheel 2. This latter frequency coincides with an antirresonance in the vertical receptance and a resonance in the lateral receptance. Nevertheless, it has to be taken into account that these are very low growth function values and for this reason corrugation development is not foreseeable. The values that can be observed in the growth functions due to wheel 3 or 4 are much lower than the front wheels, one order of magnitude lower. However, the highest order of magnitude of these functions is $10^{-6}$, which in general is a negligible value for the corrugation growth functions.

From all the figures it can be deduced that wheel number 2 is the most critical. Furthermore, there is a greater probability of corrugation development in the majority of the studied cases, due to Wheel 2. Consequently, although all possible combinations have been calculated, from this figure forward, only the results pertaining to Wheel 2 are shown. Nonetheless, cases have also been observed in which Wheel 4 or Wheel 1 produce the undulatory wear.

The growth functions for AFTRAV and ballasted track are shown in figure 13 for Wheel 2. The curve radius is of $1000 \mathrm{~m}$ and the vehicle speed is $140 \mathrm{~km} / \mathrm{h}$, the same 
as in the previous figure. Given these speed, radius and wheel parameters, the track demonstrating the least corrugation tendency is the AFTRAV track (see fig. 13 and fig. 12.b). In addition, the ballasted track and the STEDEF track show a similar corrugation tendency for these parameters. Besides, in absolute terms, all these corrugation values are very low.

(a)
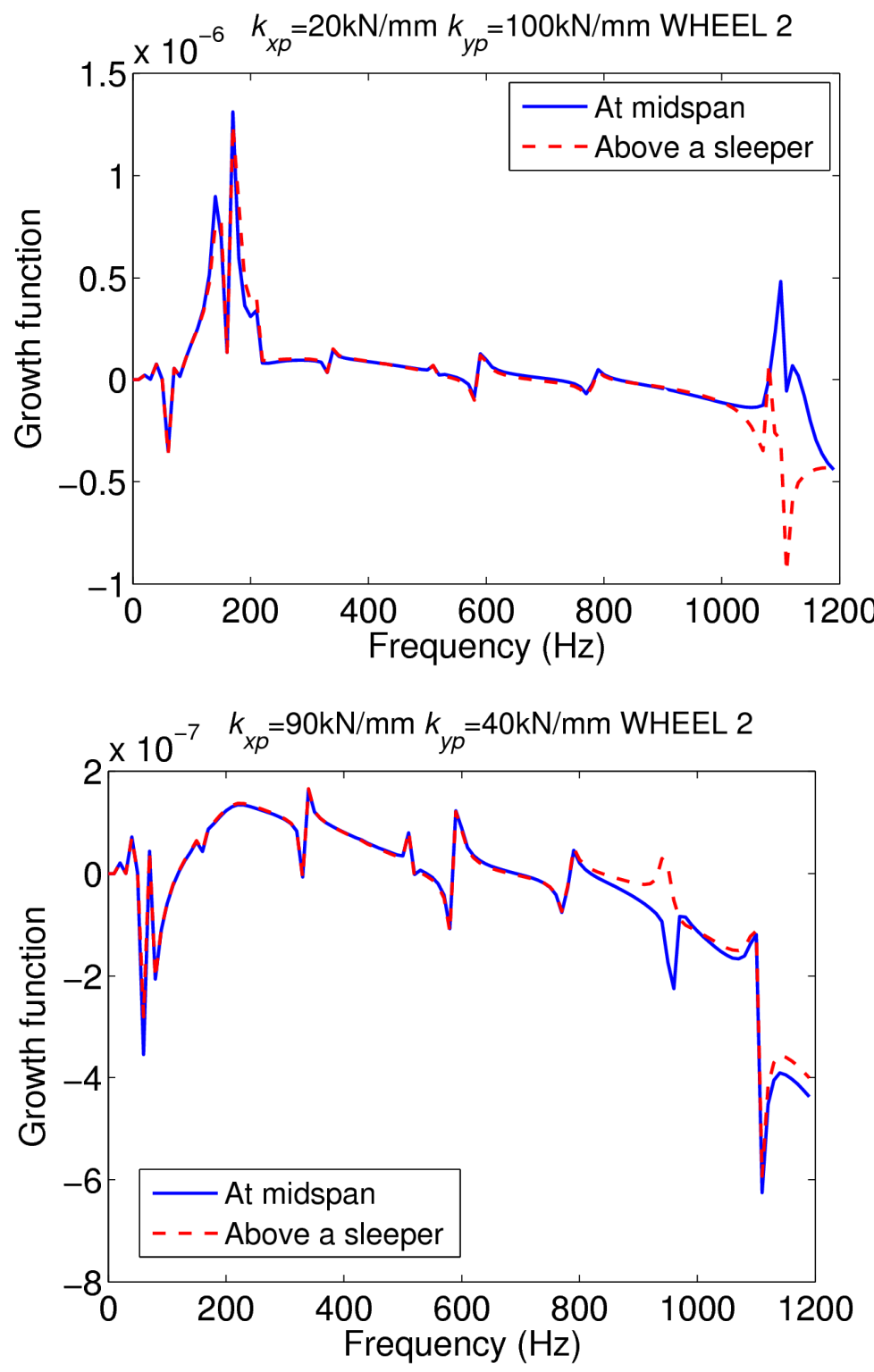

(b)

Figure 13. Growth functions for a speed of $140 \mathrm{~km} / \mathrm{h}$ and a curve radius of $1000 \mathrm{~m}$ caused by Wheel 2 a) for ballasted track and b) for AFTRAV track

As logically expected, the decrease of the curve radius leads to an increase in the corrugation growth tendency for all the tracks. This way, the orders of magnitude for the growth functions have been found to be: $10^{-7}$ for the $3550 \mathrm{~m}$ radius, $10^{-6}$ for the $1000 \mathrm{~m}$ radius, $10^{-4}$ for the $320 \mathrm{~m}$ radius, and $10^{-3}$ for the $150 \mathrm{~m}$ radius. This is reflected in figures 14 and 12.b, in which the results for each case have been shown for Wheel 2 and STEDEF track.

These figures proof that the growth functions for the two highest curve radii show a small tendency for the development of undulatory wear. In fact, the observed values of the growth function in real cases in which corrugation has developed were of the 
order of $10^{-3}$ to $10^{-2}$. In contrast, the values of the highest two radii were 3 to 5 orders of magnitude less.

(a)

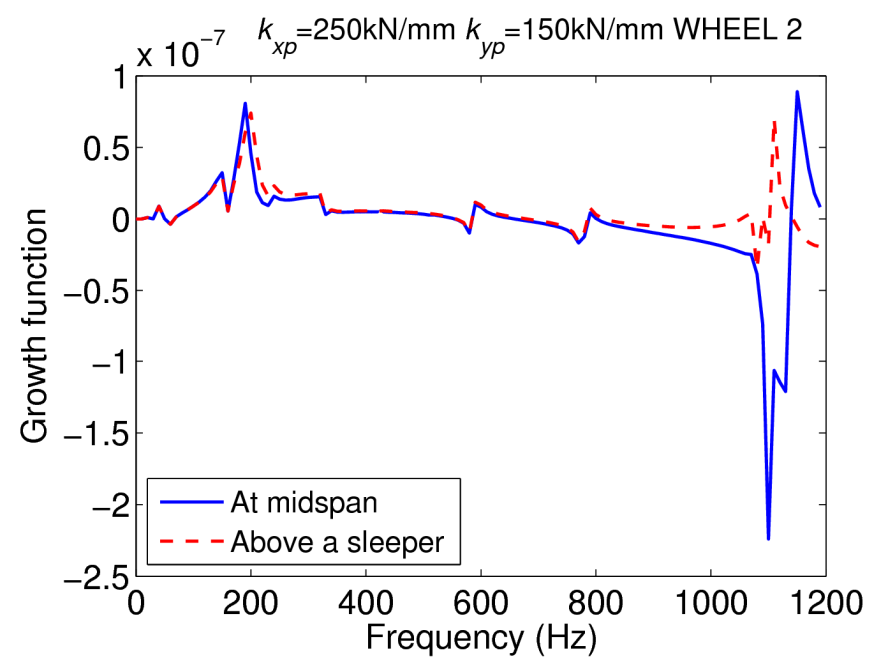

(b)

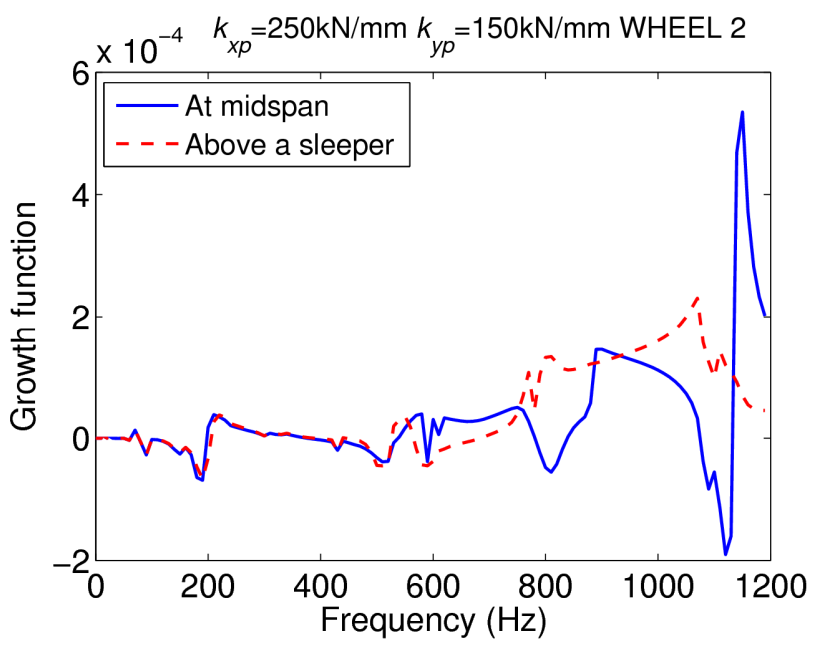

(c)

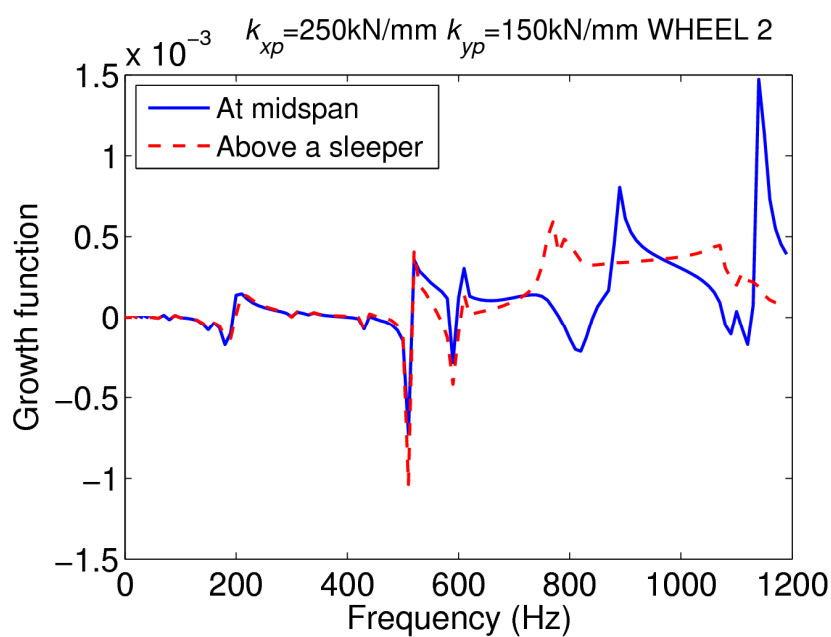

Figure 14. Growth functions for STEDEF track and Wheel 2 a) V=250km $/ \mathrm{h}$ and $\mathrm{R}=3550 \mathrm{~m} \mathrm{~b}) \mathrm{V}=45 \mathrm{~km} / \mathrm{h}$ and $\mathrm{R}=320 \mathrm{~m} \mathrm{c)} \mathrm{V}=35 \mathrm{~km} / \mathrm{h}$ and $\mathrm{R}=150 \mathrm{~m}$ 
However, for the two smallest curve radii the corrugation tendency would be higher. Nevertheless, these much reduced radii would only be in very specific points of the track. In theory, trains would not pass as frequently through these points and this would require a longer period of time for the undulatory wear to develop.

In total, 96 growth functions have been calculated. Table 1 shows a summary of the results computed. In the table columns appear the types of tracks, and in the rows, the different speeds and radii. For each combination, in grey, the maximum values of the growth functions are shown and in white, the wheel that leads to those values. It can be noticed that, for two speeds and radii the lowest maximum value corresponds to the AFTRAV track. The other two speeds and radii have the lowest growth function value in the ballasted track. Nevertheless, according to our model, looking precisely into the maximum values, the track that works better from the corrugation point of view is the AFTRAV track.

Table 1. Summary table with the maximum values for the growth functions and the wheels that cause them, for the three types of track with the different speeds and radii.

\begin{tabular}{|c|c|c|c|c|}
\hline & & & & \\
\hline & & STEDEF track & Ballasted track & AFTRAV track \\
\hline \multirow{2}{*}{$\begin{array}{l}\text { Speed } 250 \mathrm{Km} / \mathrm{h} \text { and } \\
\text { radius } 3550 \mathrm{~m}\end{array}$} & Maximum values & order 1e-7 (very low) & order $0.5 \mathrm{e}-7$ & order $1 \mathrm{e}-7$ \\
\hline & Wheels & 2 and 4 & 2 and 4 & 4 \\
\hline \multirow{2}{*}{$\begin{array}{l}\text { Speed } 140 \mathrm{Km} / \mathrm{h} \text { and } \\
\text { radius } 1000 \mathrm{~m}\end{array}$} & Maximum values & $\begin{array}{c}1.7 \mathrm{e}-6(200 \mathrm{~Hz}) \text { and } \\
2 \mathrm{e}-6(1100 \mathrm{~Hz})\end{array}$ & $\begin{array}{c}1.3 \mathrm{e}-6(200 \mathrm{~Hz}) \text { and } \\
1.3 \mathrm{e}-6(1100 \mathrm{~Hz})\end{array}$ & $1.2 \mathrm{e}-6(950 \mathrm{~Hz})$ \\
\hline & Wheels & 2 and 1 & 2 and 1 & 1 \\
\hline \multirow{2}{*}{$\begin{array}{l}\text { Speed } 45 \mathrm{Km} / \mathrm{h} \text { and } \\
\text { radius } 320 \mathrm{~m}\end{array}$} & Maximum values & $5.4 \mathrm{e}-4(1150 \mathrm{~Hz})$ & $\begin{array}{c}3 \mathrm{e}-4 \\
(1100 \mathrm{~Hz})\end{array}$ & $\begin{array}{c}4 \mathrm{e}-4 \\
(950 \mathrm{~Hz})\end{array}$ \\
\hline & Wheels & 2 & 2 & 2 \\
\hline \multirow{2}{*}{$\begin{array}{l}\text { Speed } 35 \mathrm{Km} / \mathrm{h} \text { and } \\
\text { radius } 150 \mathrm{~m}\end{array}$} & Maximum values & $5.6 \mathrm{e}-2(1150 \mathrm{~Hz})$ & $3.3 \mathrm{e}-2(1150 \mathrm{~Hz})$ & $1.6 \mathrm{e}-2(1100 \mathrm{~Hz})$ \\
\hline & Wheels & $\begin{array}{l}2 \text { (low frequency) } \\
\text { and } 4 \text { (high } \\
\text { frequency) }\end{array}$ & $\begin{array}{c}2 \text { (low frequency) } \\
\text { and } 4 \text { (high } \\
\text { frequency) }\end{array}$ & 2 and 4 \\
\hline
\end{tabular}

\section{Conclusions}

In this paper the corrugation growth tendency has been calculated for three types of track: STEDEF, AFTRAV and high performance ballasted track.

As a first step, it has been necessary to calculate track receptances. These have been obtained using both the RACING tool developed by the authors, as well as the MSC/NASTRAN finite element program. There is very good agreement between the results obtained using both methods.

The corrugation results obtained show that, for the standard parameters used, the track which works better from the corrugation point of view is the AFTRAV, followed by the ballasted track. In addition, the greatest probability of corrugation development is principally caused by the inner wheel of the leading axle, although in 
some cases it is also due to the inner wheel of the trailing axle or the outer wheel of the leading axle.

It can also be shown, as expected, that the tendency for the development of corrugation is greater when the curve radii are smaller. For the two highest radii of $1000 \mathrm{~m}$ and $3550 \mathrm{~m}$ the probability of this type of wear appearing is low for the first radii and even lower for the second. It is possible to observe in the radii of $320 \mathrm{~m}$ and $150 \mathrm{~m}$ quite higher values of the corrugation growth function than those obtained with the other two radii. Nevertheless these radii are located in places where the trains do not circulate frequently.

\section{Acknowledgements}

The authors are very grateful to CEDEX for their support through contract PT2006-024-19CCPM, and to the Basque Government for grant BFI08.172 and for support through IT-453-10.

References

[1] S. L. Grassie, J. Kalousek, Rail corrugation: characteristic, causes and treatments, Proceed. Instit. Mechan. Engin. 207 (1993), pp. 57-68.

[2] S. L. Grassie. Rail corrugation: advances in measurement, understanding and treatment, Wear 258, Issues 7-8 (2005), pp. 1224-1234.

[3] S.L. Grassie, SL. Rail corrugation: characteristics, causes, and treatments, Proceed. Instit. Mechan. Engin. Part F-J. rail and Rapid Transit 223, Issue 6 (2009), pp. 581-596.

[4] G. Xie, S.D. Iwnicki. Calculation of wear on a corrugated rail using a threedimensional contact model, Wear 265, Issues 9-10 (2008), pp. 1238-1248

[5] L. Baeza, P. Vila, A. Roda, J. Fayos. Prediction of corrugation in rails using a non-stationary wheel-rail contact model, Wear 265, Issues 9-10, (2008), pp. 11561162 .

[6] G. Xie; S. D. Iwnicki. A rail roughness growth model for a wheelset with nonsteady, non-Hertzian contact, Vehic. Syst. Dyn. DOI: 10.1080/00423110903410518 (2010)

[7] J. Piotrowski; W. Kik. A simplified model of wheel/rail contact mechanics for nonHertzian problems and its application in rail vehicle dynamic simulations, Vehic. Syst. Dyn. Vol. 46, Issue 1 (2008), pp. $27-48$.

[8] P.A. Bellette, P.A. Meehan, W.J.T. Daniel. Contact induced wear filtering and its influence on corrugation growth, Wear 268, Issues 11-12 (2010), pp. 1320-1328.

[9] P.T. Torstensson, J.C.O. Nielsen. Monitoring of rail corrugation growth due to irregular wear on a railway metro curve, Wear 267, Issues 1-4 (2009), Pages 556561.

[10] X.S. Jin, Z.F. Wen. Effect of discrete track support by sleepers on rail corrugation at a curved track, J. Sound and Vibr. 315, Issues 1-2 (2008), pp. 279-300

[11] E.G. Vadillo, J.A. Tárrago, G. Gárate, C. Angulo, Effect of sleeper distance on rail corrugation, Wear 217, (1998), pp. 140-146.

[12] T.X. Wu, D.J. Thompson. An investigation into rail corrugation due to microslip under multiple wheel/rail interactions, Wear 258, Issues 7-8 (2005), pp. 11151125

[13] T. X. Wu; D. J. Thompson. Behaviour of the Normal Contact Force Under Multiple Wheel/Rail Interaction, Vehic. Syst. Dyn. International Journal of Vehicle Mechanics and Mobility, 1744-5159, Vol. 37, Issue 3, (2002), pp. 157 - 174. 
[14] B.E. Croft, C.J.C. Jones, D.J. Thompson. Modelling the effect of rail dampers on wheel-rail interaction forces and rail roughness growth rates, J. Sound Vibr. 323, Issues 1-2, (2009), pp.17-32.

[15] M. Ishida, Takumi Ban, Kohei Iida, Hiroaki Ishida, Fusayoshi Auki. Effect of moderating friction of wheel/rail interface on vehicle/track dynamic behaviour, Wear 265, Issues 9-10, (2008), pp. 1497-1503.

[16] O. Arias-Cuevas, Z. Li, R. Lewis, E.A. Gallardo-Hernández. Rolling-sliding laboratory tests of friction modifiers in dry and wet wheel-rail contacts, Wear 268, Issues 3-4, (2010), pp. 543-551.

[17] W. J. T. Daniel; C. -Y. Cheng; P. A. Meehan. Modelling the effects of friction modifiers on rail corrugation in cornering, Vehic. Syst. Dyn., Vol. 46, Issue 9, (2008), pp. $845-866$.

[18] I. Gómez, E.G. Vadillo, A linear model to explain short pitch corrugation on rails, Wear 255, (2003), pp. 1127-1142.

[19] J. Gómez, E.G. Vadillo, J. Santamaría, A comprehensive track model for the improvement of corrugation models, J. Sound Vibr. 293 Issues 3-5, (2006), pp. 522534.

[20] J. Santamaría, E.G.Vadillo, J.Gómez, A comprehensive method for the elastic calculation of the two-point wheel-rail contact, Vehic. Syst. Dyn. 44 (supl), (2006), pp. 240-250.

[21] I. Gómez, E.G. Vadillo, An explanation of special case of booted sleeper track rail corrugation, Wear 251, (2001), pp. 916-924.

[22] C. O. Frederick, A rail corrugation theory, Proceed. of the Int. Symp. Contact Mechanics and Wear of Rail/ Wheel Syst., Kingston, Rhode Island, 1986, pp. 181211.

[23] O. Oyarzabal, J. Gómez, J. Santamaría, E.G. Vadillo. Dynamic optimization of track components to minimize rail corrugation, J. Sound Vibr., Vol. 319, Issues 3-5, (2009), pp. 904-917.

[24] Gry, L. Dynamic modelling of railway track based on wave propagation, J. Sound Vibr. 195 Issue 3, (1996), pp. 477-505. 